\title{
Aplysia Cell Adhesion Molecules and Serotonin Regulate Sensory Cell-Motor Cell Interactions during Early Stages of Synapse Formation in vitro
}

\author{
Hui Zhu, Fang Wu, and Samuel Schacher \\ Center for Neurobiology and Behavior, Columbia University College of Physicians and Surgeons, New York State \\ Psychiatric Institute, New York, New York 10032
}

Long-term facilitation of sensorimotor synapses of Aplysia in culture by serotonin (5-HT) is accompanied by two changes: an increase in the number of sensory cell branches and varicosities contacting the major axons of the target motor cell L7, and a downregulation of Aplysia cell adhesion molecules (apCAM) from the surface of the presynaptic sensory cell. We tested the hypothesis that the two changes may be linked; the 5-HT-induced decrease of apCAM levels from sensory neurites may defasciculate sensory neurites from each other and make the surface of the motor axons a more attractive substrate for new growth and synapses. We used developing cultures to examine the relationship of neuritic branching, varicosity formation, and efficacy of the connections formed by sensory cells to levels of apCAM expression on the motor cell. We then determined the consequences of 5-HT applied during the early period of interaction between sensory and motor cells (day 1 or 2 in culture) on the pattern of sensory cell growth and synapse formation. We report that the number of sensory cell branches and varicosities, and the ability of sensory growth cones to fasciculate with L7 axons and form chemical connections correlate with the level of apCAM expression on different regions of L7. Early exposure to 5-HT increased the number of sensory cell branches and varicosities contacting newly regenerated distal neurites of L7 to levels that would normally occur when the sensory neurites interact with the major proximal axons of L7. Treatment with 5-HT also modulated the efficacy of the developing synaptic connections. The change in synapse efficacy was accompanied by an increase in the formation of new sensory varicosities and branches with pioneering growth cones extending on the major axons of L7. The results are consistent with the hypothesis that treatment with 5-HT modulates local differences in the expression of cell adhesion molecules on the surface of the interacting cells making motor neurites more attractive for sensory growth cones, thereby affecting new sensory neuritic growth and synapse formation.

IKey words: growth cones, varicosities, synapse formation, 5-HT, sensory neurons, Aplysia cell adhesion molecule]

\footnotetext{
Received Mar. 18, 1994; revised May 12, 1994; accepted May 26, 1994.

We thank Drs. J. Koester, I. Kupfermann, and Z. Sun for their comments on earlier drafts of the manuscript, and Robert Woolley for help in preparing the figures. This work was supported by NIH Grants NS27541 and GM32099.

Correspondence should be addressed to Samuel Schacher, Center for Neurobiology and Behavior, Columbia University College of Physicians and Surgeons, New York State Psychiatric Institute, 722 West 168th Street, New York, NY 10032.

Copyright (C) 1994 Society for Neuroscience $0270-6474 / 94 / 146886-15 \$ 05.00 / 0$
}

The precise wiring of the nervous system during development is established by a multistep process that includes guidance of axonal pathways, recognition of postsynaptic targets, formation of synapses, and activity-dependent stabilization or elimination of synapses. The local cues that influence each of these steps in development include diffusible substances released by neighboring cells that affect direction or motility of the growth cones (Lumsden and Davies, 1983; Haydon et al., 1984; Tessier-Lavigne et al., 1988; Klar et al, 1992; Pini, 1993; Peter et al., 1994). In addition, the expression and distribution of specific extracellular matrix or cell adhesion molecules and their regulation by electrical or biochemical activity may contribute to axon guidance and synapse formation (Rutishauser et al., 1988; Landmesser et al., 1990; Bixby and Harris, 1991; Edelman and Cunningham, 1991; Reichardt and Tomaselli, 1991; Takeichi, 1991; Greenningloh and Goodman, 1992). However, the nature of the intercellular and intracellular signaling mechanisms associated with initiating synapse formation between appropriate partners, and of the role of activity in the maturation or stabilization of the newly formed synapses remain poorly understood.

The immunoglobulin-like (Ig) family of cell adhesion molecules present in both invertebrates and vertebrates appear to play critical roles throughout neural development including axonogenesis (Diamond et al., 1993), pathfinding(Edelman, 1983; Rutishauser and Jessell, 1988; Furley et al., 1990), and synapse formation (Fraser, 1980; Chow, 1990; Landmesser et al., 1990; Cunningham and Edelman, 1991). ApCAM, or Aplysia cell adhesion molecule, is a major cell surface glycoprotein expressed on most neurons in the CNS of Aplysia from the earliest stages of development through adult life (Keller and Schacher, 1990; Schacher et al., 1991). ApCAM isoforms are homologous to members of the Ig family of cell adhesion molecules represented by vertebrate NCAM and Drosophila fasciclin II (Mayford et al., 1992). The highest levels of expression in both the developing and mature CNS of Aplysia are in the neuropil region of the ganglia or in the synaptosome fraction (Keller and Schacher, 1990; Schacher et al., 1991). Consistent with the in vivo distribution, apCAM is expressed at the highest levels at sites of synaptic interaction between sensory and motor cells in cell culture (Keller and Schacher, 1990).

Support for the role of apCAM in synapse formation comes from studies on long-term functional and structural plasticity of the sensorimotor synapse. Long-term facilitation by 5-HT is accompanied by the formation of new sensory branches and varicosities (Montarolo et al., 1986; Glanzman et al., 1990). By contrast, long-term depression of the same synapse by the neuropeptide Phe-Met-Arg-Phe-amide (FMRFamide) is accom- 
panied by the loss of presynaptic sensory neurites and varicosities (Montarolo et al., 1988; Schacher and Montarolo, 1991). Both forms of plasticity are also accompanied by a rapid and cell-specific change in the distribution of apCAM. Treatment with 5-HT evokes a downregulation of apCAM from the surface of the sensory cell via a cAMP-dependent increase in endocytosis of clathrin-coated vesicles (Bailey et al., 1992; Mayford et al., 1992; $\mathrm{Hu}$ et al., 1993). On the other hand, FMRFamide causes a downregulation of apCAM from the surface of the target motor cell by a similar cAMP-dependent mechanism (Peter et al., 1994; Wu and Schacher, 1994). The changes in apCAM distribution on either the presynaptic (facilitation) or the postsynaptic (inhibition) cell correlate with the expression of the long-term functional and structural changes (Bailey et al., 1992; $\mathrm{Wu}$ and Schacher, 1994). The changes in apCAM distribution also correlate with changes in the behavior of growth cones interacting with neurites of homologous cells (Peter et al., 1994). These results suggest that cell-specific differences in the distribution of apCAM, and extrinsic factors that may regulate the expression of these molecules on presynaptic versus postsynaptic cells may affect growth cone behavior during interactions with target cells both during the early stages of synapse formation and at later stages when mature neural circuits are modified by stimuli evoking behavioral plasticity.

We report here that the cell- and region-specific level of expression of apCAM and the cell-specific modulation of that expression by 5-HT may contribute significantly to the overall pattern of neurite outgrowth, the extent of presynaptic celltarget interaction, and synapse formation. The results support the hypothesis that local differences in expression of cell adhesion molecules on the presynaptic cell and the postsynaptic target may influence target selection and synapse formation.

\section{Materials and Methods}

Cell culture. Mechanosensory neurons of Aplysia were isolated from pleural ganglia dissected from adult animals $(70-100 \mathrm{gm})$ and cocultured either with homologous sensory cells or with identified motor cell L7 isolated from the abdominal ganglion of juvenile animals (1-3 gm; Howard Hughes Medical Institute Mariculture facility, Miami, FL) and maintained for 2-4 d as described previously (Schacher and Proshansky, 1983; Schacher, 1985; Rayport and Schacher, 1986; Glanzman et al., 1990). Each SN-L7 culture contained a single L7 cocultured with one or two sensory cells. Cells were isolated with the proximal segments of their original axons (100-200 $\mu \mathrm{m}$ for sensory cells and $250-800 \mu \mathrm{m}$ for L7). The placement of the sensory cells with respect to the motor cell was dependent on the nature of the experiment. To quantify the regional differences in the structure of sensory neurons when interacting with the motor targets, a single sensory cell was plated such that its axon stump was $100-500 \mu \mathrm{m}$ from the original proximal axons of L7 (initial segment, axon stump, or between the two). To study the effects of 5-HT (Sigma, St. Louis, MO) or pretreatment of the motor cell L7 with high levels of anti-apCAM mAb on both synapse formation and sensory cell structure, a single sensory cell was plated with its cut axon stump near $(0-100 \mu \mathrm{m})$ the proximal axons of the motor cell. To examine the effect of 5-HT on sensory cell growth near the newly regenerated motor or sensory neurites, two sensory cells were plated either with a third sensory cell or with a motor cell such that their axon stumps were more than $500 \mu \mathrm{m}$ from either the cell body or axon stump of the target sensory or motor cell. To examine regional differences in the distribution of apCAM, individual motor cells and two to four sensory cells were plated in the same culture dish but far apart so that their neurites did not interact.

Treatments. For experiments examining the effects of 5-HT, each SNL7 or SN-SN coculture was exposed to either control solution [perfusion medium; $1: 1$ by volume of L-15 medium (Sigma) with appropriate salts added to reflect marine environment of Aplysia and seawater (Instant Ocean); Montarolo et al., 1988] or to $2.5 \mu \mathrm{M} 5$-HT (Sigma) in perfusion medium. The cultures were exposed to these solutions for two $1 \mathrm{hr}$ periods, each period followed by two washes of $10 \mathrm{ml}$ of perfusion medium at $10 \mathrm{~min}$ intervals to remove each control or 5-HT application. The cultures were then rinsed with standard culture medium (Aplysia hemolymph and L15; Schacher and Proshansky, 1983) and returned to the incubator $\left(18^{\circ} \mathrm{C}\right)$. For experiments examining the consequences of anti-apCAM mAb on synapse formation, the motor cell $\mathrm{L} 7$ was plated alone and allowed to regenerate for $1 \mathrm{~d}$. Each $\mathrm{L} 7$ culture was treated either with anti-apCAM mAb $(4 \mathrm{E} 8 ; 250 \mu \mathrm{g} / \mathrm{ml})$ or control $\mathrm{IgG}$ antibodies $(250 \mu \mathrm{g} / \mathrm{ml})$ for $5 \mathrm{hr}$ using a blind protocol. The antibodies were washed out with perfusion medium and standard culture medium and a single sensory neuron was added to each dish with its stump 50-100 $\mu \mathrm{m}$ from the proximal motor axon. Control and experimental cultures were examined $24 \mathrm{hr}$ later for the efficacy of the synaptic connection and for the pattern of sensory-motor interaction using intracellular dye injection.

Electrophysiology. The stimulation and recording techniques for measuring the amplitude of the EPSP evoked in $\mathrm{L} 7$ in cocultures have been described (Montarolo et al., 1986, 1988; Dalc ct al., 1988; Schacher et al., 1990; Ghirardi et al., 1992). After 1 or $2 \mathrm{~d}$ in culture, the motor cell was impaled with a microelectrode (15-20 M 2 ) containing $2.0 \mathrm{M}$ $\mathrm{KCl}$ and held at a potential of $-30 \mathrm{mV}$ below the resting level to permit accurate measurement of the amplitude of the EPSP. The amplitudes of the EPSPs for the same cultures were retested a day later and for some cultures on day 4 as well. Control solution or 5-HT was added to the cultures on day one either after recording the amplitude of the EPSP or after photographing the structure of the sensory cell (see below). Synaptic potentials were evoked in L7 by stimulating each sensory cell with a brief $(0.4-0.6 \mathrm{msec})$ depolarizing pulse sufficient to fire a single action potential using an extracellular electrode placed near the cell body of the sensory neuron. Cultures were matched by the amplitude of their initial EPSP and divided into control and 5-HT-treated groups.

Dye injection and imaging structural changes. The fluorescent dye 5(6)-carboxyfluorescein (Molecular Probes; $6 \%$ in $0.44 \mathrm{M} \mathrm{KOH;} \mathrm{pH} 7.0$ ) or lissamine rhodamine (Gurr; $5 \%$ in water) was injected into each sensory cell immediately after recording the amplitude of the EPSP on day 1 and day 2 with $0.4-0.6 \mathrm{nA}$ hyperpolarizing current pulses (500 msec at $1 \mathrm{~Hz}$ ) for 5-6 min (Glanzman et al., 1989; Schacher and Montarolo, 1991). For experiments on sensory cell interaction with distal motor neurites or with other sensory neurites, dye was injected on day 2 and day 3. Nomarski or phase contrast and fluorescent images of the same view areas either along the major axons of the motor cell, along the distal motor neurites, or other sensory neurites were taken on a Nikon Diaphot microscope with an SIT (Dage) video camera. The images were processed by a Dell 310 computer with a PC Vision Plus frame grabber, and subsequently stored on a Storage Dimension or Panasonic optical disk drive. Alignment of the live view area with the first recorded image was aided by the computer with fine adjustments made with manual rotation of the culture dish. Illumination used for obtaining fluorescent images was kept as low as possible to prevent photodamage. To minimize differences in imaged structures that might arise as a result of differences in the extent of dye filling, light intensities used on the second day were adjusted to match the intensity of the stored images taken on the first day. Micrographs of the images were made with a Panasonic or Sony video printer.

Quantification of structural change. Counts of the number of varicosities, branches, and growth cones of sensory neurons, and measurements of sensory neurite lengths were obtained from fluorescent images of sensory neurites contacting either the distal neurites or the major axons of L7. Because the cultures were photographed with a relatively low-power $(20 \times)$ objective lens, most if not all the neurites and varicosities contacting the motor cell in a given region could be viewed in a single photograph. Since the major axons of L7 are relatively thick structures, it was necessary in some cases to photograph a second focal plane to image all of the labeled neurites in a given view area. The matched fluorescent images of each focal plane for the two time points were compared and the total number of varicosities, branches, and growth cones counted. Net change was measured for all treatments. We did not examine the effect of treatment on the turnover of preexisting varicosities or neurites. Structures that were round or slightly elongated ellipses greater than or equal to $2.5 \mu \mathrm{m}$ and connected by narrow neuritic necks were counted as varicosities (Bailey and Chen, 1983, 1988). Growth cones were identified as elongated structures on the ends of neurites with fine-diameter filopodia. Counts were performed blind; the individual did not know the amplitude of the EPSPs before or after treatment or the nature of the treatments. 
ApCAM immunofluorescence and distribution. SN-L7 cocultures, or cultures of isolated motor cell L7 along with isolated sensory cells were rinsed two times at $30 \mathrm{~min}$ intervals with perfusion medium and exposed for $30 \mathrm{~min}$ to FITC-conjugated anti-ApCAM monoclonal antibody (mAb 4E8; $10-20 \mu \mathrm{g} / \mathrm{ml}$ ) dissolved in perfusion medium (Keller and Schacher, 1990; Mayford et al., 1992; Peter et al., 1994; Wu et al., 1994). Unbound $\mathrm{mAB}$ was washed out with perfusion medium. Axons and neurites of each cell in a given culture dish were photographed at the same fluorescent light intensity (Mayford et al., 1992; Peter et al., 1994; Wu et al., 1994). Average fluorescent intensities were measured along the entire length of the primary motor axon from cell body to axon stump (200$600 \mu \mathrm{m}$ ), and compared to average intensity measured for the newly regenerated ncurites cmerging from the axon stumps. These values were compared to the average fluorescent intensities of sensory neurites and growth cones regenerated by cells plated in the same dish as the motor cells. For each culture the intensity values for each region were normalized relative to the value obtained for the sensory cell growth cones. Each culture dish provided a single set of ratios that were then averaged to obtain final values.

Analysis of data. All data are represented as the mean \pm SEM (standard error of the mean). Student's $t$ tests (two tailed) or ANOVAs (one or two factor) followed by corrected multicomparison $t$ tests (Bonferroni) were used to measure significance of the changes in EPSP or sensory cell structure. Differences were considered significant when $p$ values were less than 0.05 .

\section{Results}

Branching and formation of varicosities by SNs are associated with high levels of apCAM on $L 7$

Earlier studies described qualitatively the effects of the original proximal axons of $\mathrm{L} 7$ on the pattern of growth and structure of sensory cell neurites and varicosities in culture (Glanzman et al., 1989, 1990, 1991). These proximal axons of $L 7$ served as an excellent substrate for neuritic growth. In addition, the sensory varicosities located on the original proximal axons contain transmitter release sites while sensory varicosities contacting the more distal newly regenerated motor neurites did not contain mature properties of transmitter release sites (Glanzman et al., 1989). We first quantificd the regional variations in the sensory cell neuritic structure by comparing the structure of sensory neurites interacting with distal neurites of L7 with the neurites of the same sensory cell interacting with the original proximal axons of L7. We then determined whether differences in apCAM levels expressed on proximal motor axons and distal motor neurites correlate with the overall structure of the sensory neurons and the ability to form chemical connections.

Single sensory cells were plated such that their neurites would first encounter newly regenerated distal neurites of $\mathrm{L} 7$ before making contact with different areas of the original proximal axons of L 7 - intermediate zones ( $N=3$; Fig. 1), cell body and axon hillock $(N=3$; Fig. $2 A)$, or motor axon stump $(N=3$; Fig. $2 B$ ). After $3 \mathrm{~d}$ in culture, each sensory cell was injected with fluorescent dye and sensory neurites extending toward the original proximal axons of L7, and those near or in contact with the axons were photographed. As previously reported, the original proximal axons of $\mathrm{L} 7 \mathrm{had}$ a significant effect on the number of sensory cell branches and varicosities (Figs. 1, 2). Although the basic pattern of sensory neurite growth was not influenced by the location of the initial interaction of the sensory neurites with the original motor axons, the location of this interaction influenced the subsequent directions of sensory growth. Relatively large-diameter sensory neurites, formed primarily by fasciculated bundles of finer-diameter neurites (Schacher and Proshansky, 1983; Glanzman et al., 1989) with few varicosities, extended along the substrate or the regenerated distal motor neurites. With contact along the major motor axons after $3 \mathrm{~d}$ in culture, their was a twofold increase in the total number of branches $(198 \pm 29 \% ; N=9 ; p<0.005)$ and ncarly a threcfold increase in the number of varicosities $(287 \pm 45 \% ; N=9 ; p<$ 0.005 ) compared to that found for sensory neurites interacting with regenerated distal motor neurites. Sensory neurite growth following contact with the original motor axons appeared directed so that the individual sensory neurites retain close apposition to the original motor axons. Contact by the large sensory neurites in the middle of the motor axon (Fig. 1) was followed by bidirectional sensory growth, while contact at either end of the motor axons (Fig. 2) was followed by unidirectional growth along the original motor axons.

One factor affecting the overall pattern and direction of sensory cell growth may be the high level of apCAM on the surface of the original motor axons (Peter et al., 1994; Wu et al., 1994) relative to the apCAM levels on the distal motor neurites or on the sensory neurites themselves. Significant changes in the pattcrn of sensory cell growth may not be triggered by contact with the distal regenerated neurites of $\mathrm{L} 7$, because the relative differences in apCAM expression between the sensory and motor neurites are too small. To test this hypothesis, we examined the relative ratio of apCAM expression for different regions of $\mathrm{L} 7$ and sensory cells maintained under the same growth conditions to that expressed by the sensory cell growth cones $(N=6 \mathrm{cul}-$ tures). After staining live cells with FITC-conjugated anti-apCAM $\mathrm{mAb}$, we photographed the cells and measured the average fluorescence intensity for the axons and neurites of the motor and sensory cells (Fig. 3). Compared to the level of anti-apCAM fluorescence expressed on the growth cones of sensory cells (normalized to a level equal to 1 ), the level expressed on the original axons of $\mathrm{L} 7$ was nearly sixfold greater $(5.76 \pm 0.83)$. The level of anti-apCAM fluorescence expressed on the distal motor neurites was twofold higher $(2.06 \pm 0.15)$ than sensory growth cones. Sensory neurites expressed levels that were about $40 \%$ higher than the growth cones $(1.42 \pm 0.13)$. The difference in staining intensity between proximal motor axon and distal motor neurites is not a consequence of more membrane, since the distal motor neurites contain stacks of fine-diameter processes while the proximal motor axons contain primarily the original large-diameter axons (Schacher and Proshansky, 1983).

These data are consistent with the hypothesis that one feature that makes the original proximal axons of $\mathrm{L} 7$ most attractive for sensory cell growth cones and the formation of varicosities may be the relatively high levels of apCAM expression compared to the level expressed on the distal motor neurites or the sensory neurites themselves. As growth cones of sensory neurites contact the proximal motor axon they defasciculate from other sensory neurites to extend as separate processes along the surface of the proximal motor axon. The relatively small difference between apCAM expression on the distal motor neurites compared to the neighboring sensory neurites may not be large enough to alter the pattern of sensory growth while interacting with distal L7 neurites. To test these predictions, we examined the changes in the pattern of sensory cell growth and in synapse formation when only the motor cells are treated with levels of anti-apCAM antibodies that evoke defasciculation of homologous neurites (Keller and Schacher, 1990; Peter et al., 1994).

The pattern of sensory neurite outgrowth and the formation of chemical connections were altered significantly by pretreat- 

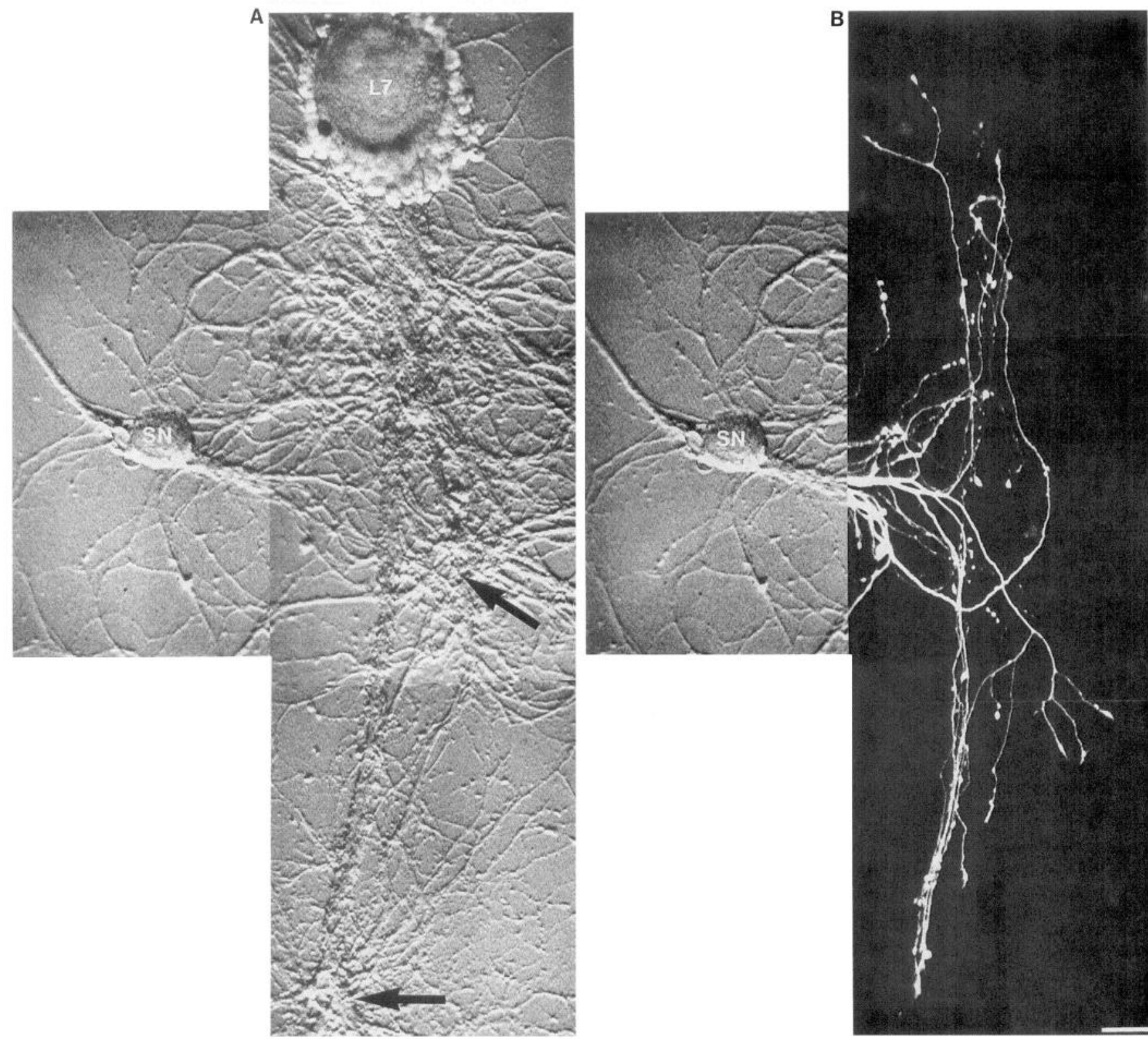

Figure 1. The major axons of motor cell L7 change the pattern of growth by the presynaptic sensory cell. $A$, Nomarski contrast micrograph of a sensory neuron (SN) cocultured with motor cell L7 (L7) for $3 \mathrm{~d}$. The axon stump of the sensory cell is about $200 \mu \mathrm{m}$ from the middle region of the major motor axons that emerge from the cell body of L7 and extend toward the bottom of the photograph. The stumps of the L7 axons are indicated by the arrows (at the bottom of the photograph, and in the middle of the photograph at the level of the sensory cell and its axon). $B$, Collage of Nomarski contrast view of the sensory neuron and epifluorescence view of the sensory neurites emerging from the stump of the sensory neuron and interacting with motor neurites and axons following intracellular injection of carboxyfluorescein. Note that the sensory neurites extend primarily as thick bundles until reaching close to or following contact with the major axons of L7. Sensory neurites then form many branches studded with varicosities and extend primarily both up (toward cell body) and down (away from cell body) the major axons of L7. Scale bar, $50 \mu \mathrm{m}$.

ment of L7 with anti-apCAM mAb (Fig. 4). Treatment with the control IgG had no effect on the pattern of expression and distribution of apCAM (Fig. $4 A I$ ) or the pattern of sensory neuritic growth when interacting with the major axons of L7 (Fig. 4A2,A3). Sensory neurites defasciculated from each other and refasciculated on the motor axon. The average amplitude of the EPSP was $6.8 \mathrm{mV} \pm 2.7(N=6)$. Pretreatment of L7 with anti-apCAM $\mathrm{mAb} 24 \mathrm{hr}$ earlier resulted in marked decrease in the intensity of anti-apCAM fluorescence from remaining unbound apCAM on the surface of $\mathrm{L} 7$ (Fig. $4 B 1$ ). Treatment also resulted in the failure of most of the sensory neurites to fasciculate on the proximal motor axons (Fig. 4B2,B3). The neurites either extended across and beyond the motor axon (Fig. 4B3), stopped growing upon reaching the motor axon, or extended parallel to the motor axon following a turn. This failure to fasciculate with the motor axon was correlated with a failure to form connections (four of six cultures) such that the average EPSP amplitude was only $0.5 \mathrm{mV} \pm 0.3(N=6 ; p<0.001)$. Thus, altering the normal difference in the level of apCAM expression on the surfaces of the sensory and motor cells can have a profound effect on the overall pattern of interaction and the formation of synaptic connections (Hawver and Schacher, 1993). 


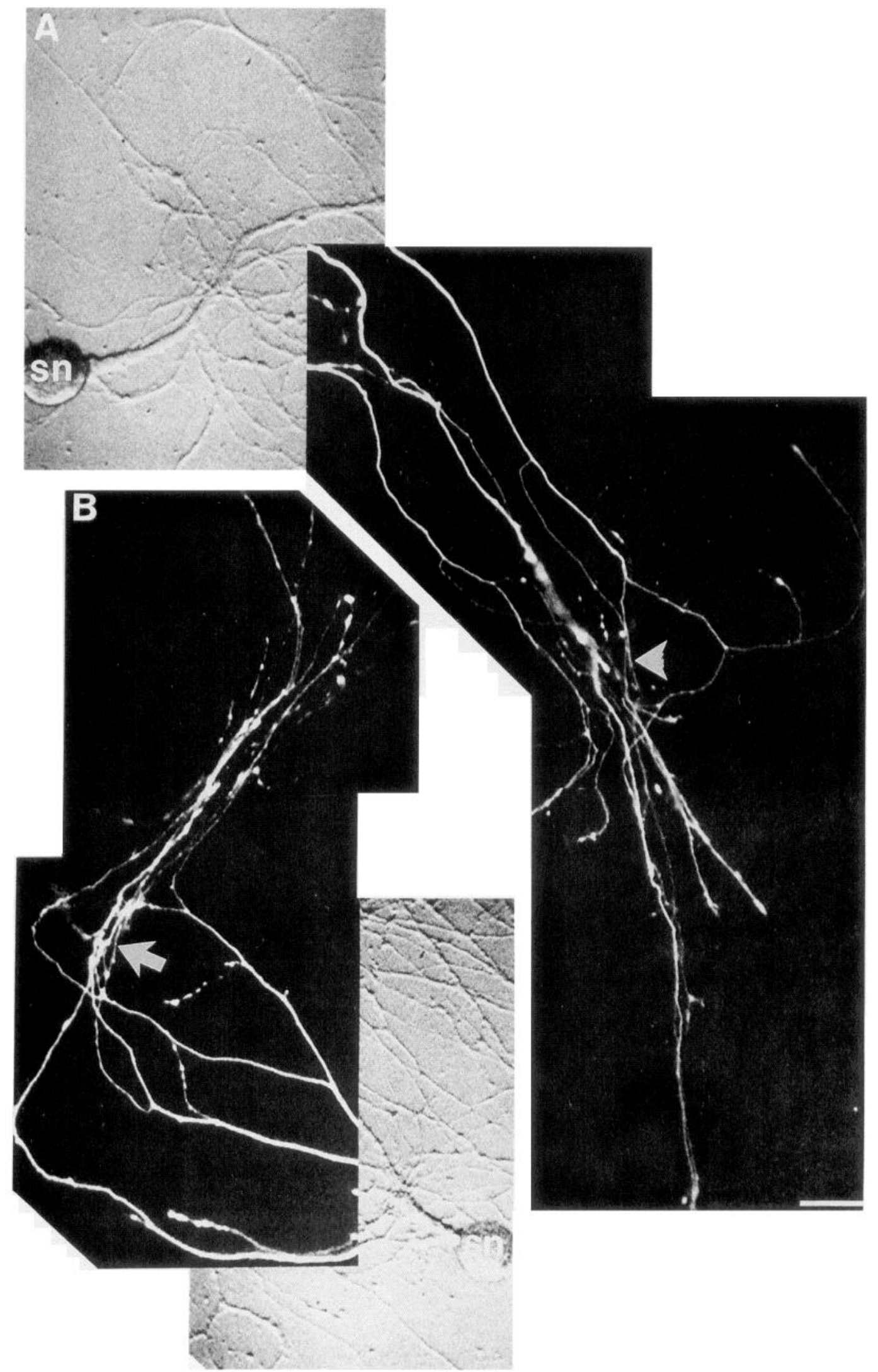

Figure 2. The major axons of target motor cell L7 dictate both direction and pattern of growth of sensory cell neurites. $A$ and $B$, Collage of Nomarski contrast and epifluorescent views of neurites of a sensory neuron (SN) following intracellular injection of the dye into the SNs $3 \mathrm{~d}$ after plating. The sensory neurons were plated either near the cell body/initial segment of L7 (arrowhead in A) or near the axon stump of one of the major axons of L7 (arrow in B). Note that the relatively thick bundles of unbranched sensory neurites with few varicosities extend on the substrate 


\section{5-HT induces branching and varicosity formation by $S N$ neurites with distal $L 7$ neurites}

Previous studics indicated that transmitter applications that downregulated apCAM from the surface of neurons also evoke a decline in fasciculation by the cell's growth cones with neurites of homologous cells (Peter et al., 1994). Application of 5-HT downregulates apCAM from the surface of sensory neurites, but not motor cell L7, and reduces fasciculation of sensory growth cones with other sensory neurites, but has no effect on the interactions of L7 growth cones with other neurites of L7 (Peter et al., 1994). The same treatments with 5-HT evoke long-term facilitation of sensorimotor connections that is accompanied by a target-dependent increase in SN branches and varicosities interacting with the motor axons. Thus, the selective downregulation of apCAM from the surface of sensory neurites but not the motor cell may facilitate the formation of new branches and varicosities by first decreasing $\mathrm{SN}-\mathrm{SN}$ interactions and increasing $\mathrm{SN}-\mathrm{L} 7$ interactions leading to the formation of new synaptic contacts. These long-term changes might arise as a consequence of the transmitter-induced shift in the relative ratio of apCAM levels on the surfaces of the two cells. To test this hypothesis, we examined the long-term effects of 5-HT on the structure of sensory neurites interacting with the distal neurites of $\mathrm{L} 7$ or with the distal neurites of other sensory cells.

The structure of sensory neurites interacting with distal neurites of $\mathrm{L} 7$ after control treatment (Fig. 5) is relatively simple with few branches and varicosities compared to the structure of cells contacting the proximal axons (see Figs. 1,2). By contrast, $24 \mathrm{hr}$ after treatment with $5-\mathrm{HT}$, sensory cells elaborate many more branches and varicosities in regions of the distal motor neurites (Fig. 6). 5-HT ( $N=6$ cultures; 12 sensory cells) increased the number of new branches by $326 \pm 37 \%$ compared to a change of $178 \pm 20 \%$ in the number of new branches for controls $(N=6$ cultures; 12 sensory cells; $p<0.01)$. The differential change in the number of varicosities was even greater; $385 \pm 31 \%$ with 5 -HT treatment and $150 \pm 12 \%$ for controls $(p<0.008)$. These changes in the pattern of growth are target dependent. The overall structure of sensory neurites contacting other sensory neurites was not affected $24 \mathrm{hr}$ after treatment with 5-HT (data not shown). When reexamined $24 \mathrm{hr}$ after treatment, experimental $(N=9)$ and control $(N=8)$ cells had comparable changes in the number of new branches $(4.4 \perp 2.0$ for 5 -HT vs $4.7 \pm 1.4$ for control). The defasciculation of sensory growth cones observed immediately after treatment with 5-HT (Peter et al., 1994) was not maintained $24 \mathrm{hr}$ later when sensory neurites interact with homologous cells. Treatment with 5-HT while sensory neurites are actively growing did increase the rate of neuritic growth. Each branch extended $581.7 \pm 53.2$ $\mu \mathrm{m}$ after 5 -HT treatment compared to $316.8 \pm 33.1 \mu \mathrm{m}$ after control treatment $(p<0.002)$. These data are consistent with the hypothesis that one of the long-term actions of 5-HT, the selective downregulation of apCAM on the surface of the extending sensory neurites, but not the motor neurites, results in a change in the ratio of apCAM expression between distal motor neurites and the sensory neurites such that sensory-motor in- teractions are favored over sensory-sensory interactions. These changes, along with the direct actions on the rate of neurite extension, may affect the degree of synaptic interactions between the presynaptic cell and the target.

\section{5-HT modulates efficacy of developing sensorimotor synapse and the number of new sensory varicosities and branches with pioneering growth cones contacting original proximal axons of $L 7$}

Sensory cells form stable chemical connections with motor cell L7 after $4 \mathrm{~d}$ in culture. The efficacy of these connections and the structure of sensory neurites in contact with the original axons of $\mathrm{L} 7$ can be modulated for long durations, however, after exposure to specific neuromodulators (Montarolo et al., 1988; Schacher et al., 1990). During the first $4 \mathrm{~d}$ in culture, there is a progressive increase in the efficacy of sensorimotor connections that is correlated with a progressive increase in the number of sensory varicosities in contact with the original proximal axons of L7 (Glanzman et al., 1991; Bank and Schacher, 1992). To cxplore further the hypothesis that 5-HT enhances SN-L7 interaction, we examined how exposure to 5-HT alters the development of the connection and the structure of sensory neurites extending on the target axon.

Treating 1-d-old cultures with 5-HT had a significant and prolonged effect on the amplitude of the EPSP evoked in L7 during the first $4 \mathrm{~d}$ in culture. After measuring the amplitude of the EPSP and treating with either control solution $(N=6)$ or 5-HT $(N=6)$, the same connections were reexamined on day 2 and on day 4. 5-HT increased the efficacy of sensorimotor connections by more than twofold on day 2 (Fig. 7); the change in the amplitude of the evoked EPSP went from $11.0 \mathrm{mV} \pm$ 2.4 to $24.7 \mathrm{mV} \pm 3.4$ in controls versus a change from 12.0 $\mathrm{mV} \pm 2.1$ to $40.2 \mathrm{mV} \pm 2.4$ with $5-\mathrm{HT}$. The difference in the efficacy of the connections persisted for $48 \mathrm{hr}$. The EPSP amplitude evoked in control cultures on day 4 was $42.3 \mathrm{mV} \pm 5.5$, while the EPSP evoked in the 5-HT treated cultures was 58.7 $\mathrm{mV} \pm 1.1$. The difference on day 4 is an underestimate of the actual difference since the evoked response in L7 in five of the six cultures treated with 5-HT was an action potential (and the EPSP was scored as $60 \mathrm{mV}$ ), despite the fact that L7 was hyperpolarized by $30 \mathrm{mV}$ below the resting potential (range of resting potential was $50-59 \mathrm{mV}$ for the $5-\mathrm{HT}$ group vs a range of 47-60 $\mathrm{mV}$ for the control group).

Treatment with 5-HT also had a significant effect on the structure of the sensory neurites extending along the motor axons (Figs. 8, 9). In a second set of cultures, each sensory cell was injected with the fluorescent dye and photographed after recording the amplitude of the EPSP both on day 1 and $24 \mathrm{hr}$ later. As was observed for the other groups, the amplitude of the EPSP after treatment with 5-HT $(N=7)$ increased by more than twofold compared to the increase observed with controls $(N=7)$, an increase of $13.1 \mathrm{mV} \pm 2.8$ for controls compared to an increase of $31.9 \mathrm{mV} \pm 4.1$ for $5-\mathrm{HT}$. The increase in EPSP amplitude was accompanied by a twofold increase in the formation of new sensory varicosities $(9.7 \pm 1.6$ for control vs $20.1 \pm 1.8$ for $5-\mathrm{HT}$ ) and a nearly threefold difference in the 
A1
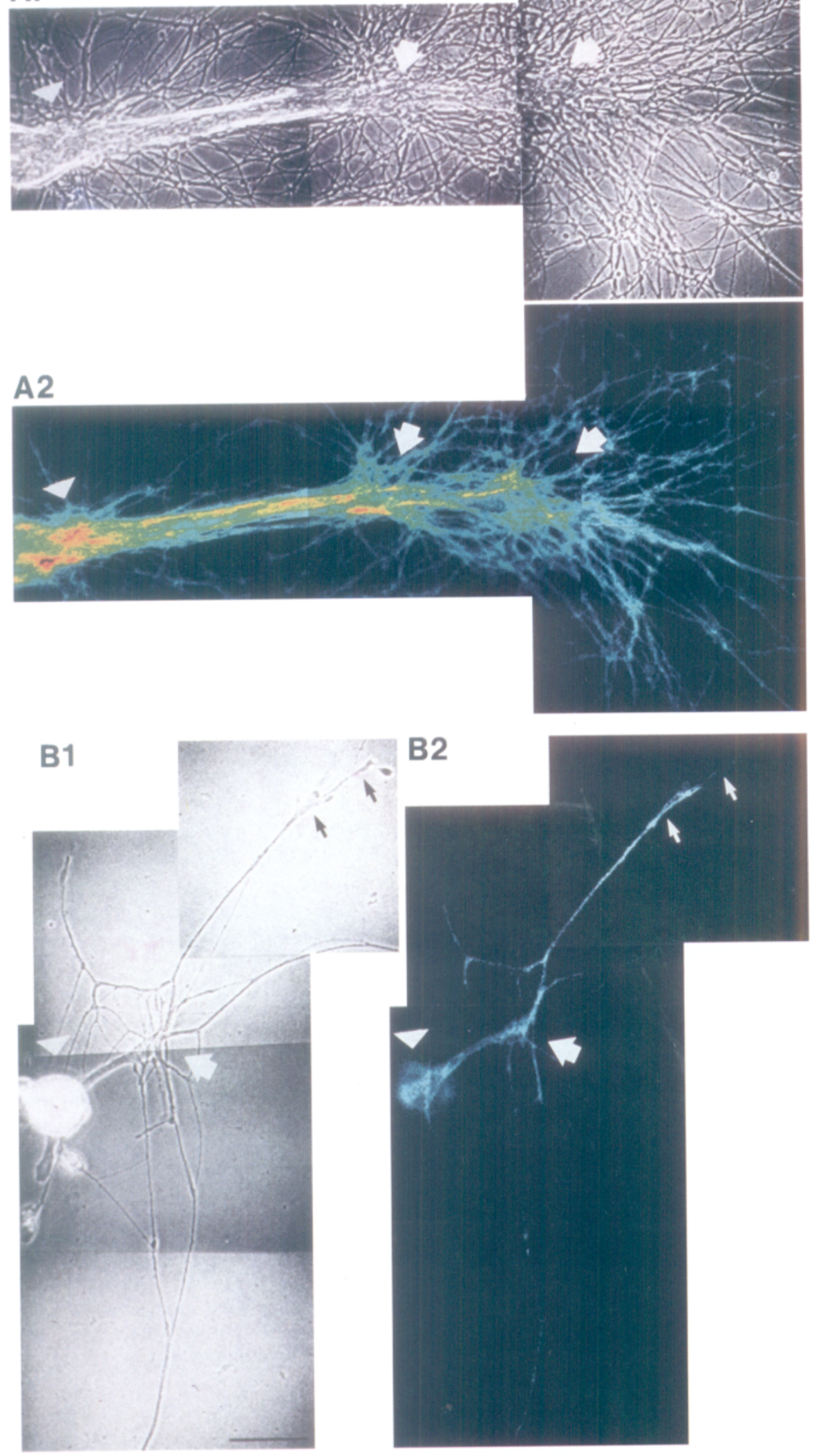

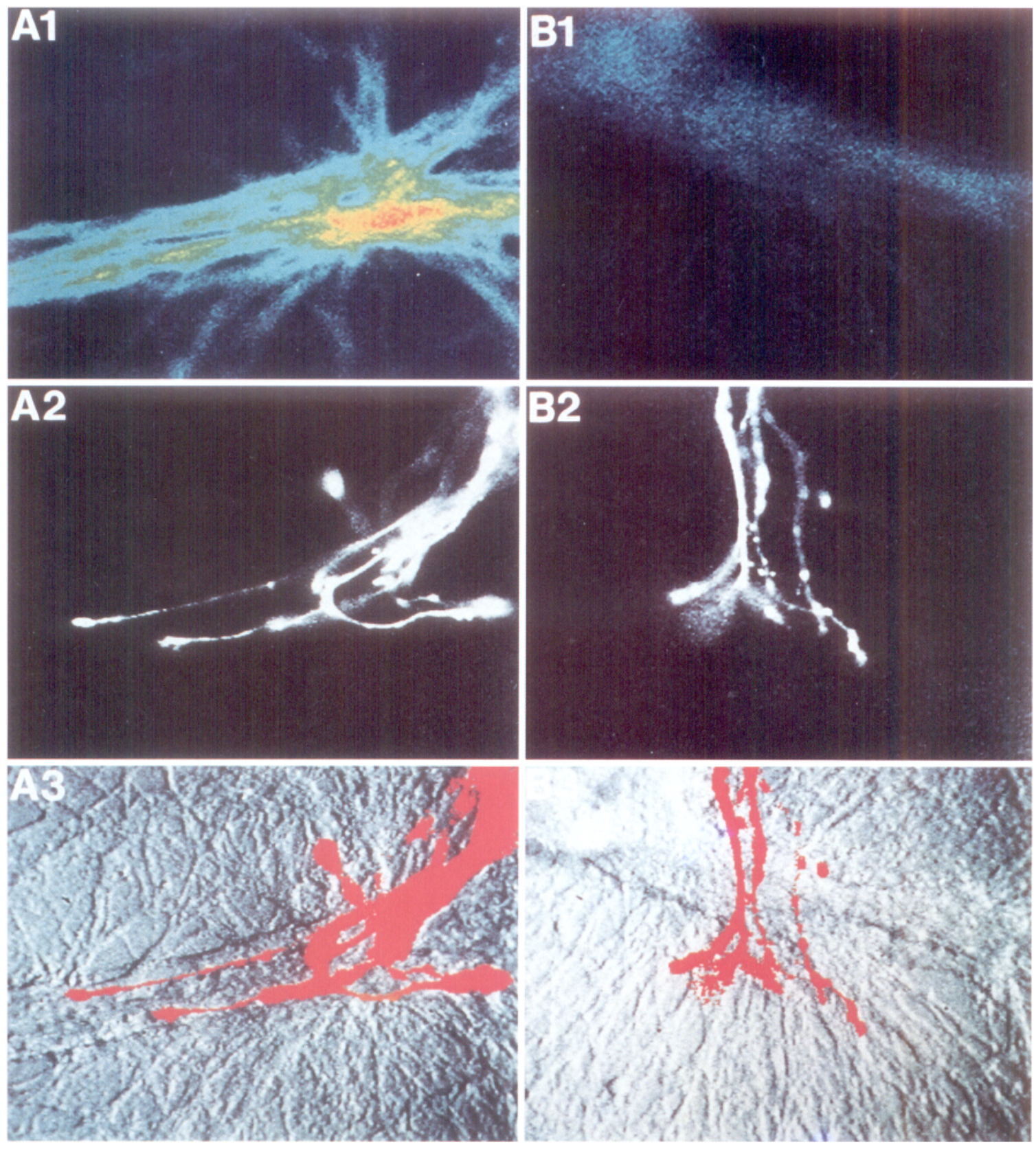

Figure 4. Anti-apCAM mAb treatment of $\mathrm{L} 7$ alters subsequent pattern of sensory-motor interaction. Distribution of apCAM and pattern of sensory neurite growth along motor axon $24 \mathrm{hr}$ following treatment with mouse $\operatorname{IgG}(A)$ or anti-apCAM mAb $(B)$. Sensory cells were added after treatment. Note the nonuniform distribution and relatively high-intensity staining of FITC-anti-apCAM along the motor axon following control treatment $(A l)$ compared to the relatively uniform and low-intensity staining following treatment with anti-apCAM mAb $(B I)$. The sensory neurites, visualized by rhodamine epifluorescence after intracellular injection of lissamine rhodamine (Glanzman et al., 1991), defasciculate from each other $(A 2)$ and extend along the main motor axon (A3) with control treatment. Following treatment with anti-apCAM mAb, sensory neurites extend (B2) and bypass the main motor axon (B3). The dye-filled sensory neurites are depicted in red and superimposed on the Nomarski view of the cocultures (A3 and $B 3)$. Scale bar, $15 \mu \mathrm{m}$.

Figure 3. Nonuniform distribution of apCAM along axons and neurites of L7 $(A)$ and sensory cell $(B)$ plated in the same dish. FITC-anti-apCAM was applied to the live culture after $4 \mathrm{~d}$ and photographed as described previously (Keller and Schacher, 1990; Mayford et al., 1992; Peter et al., 1994; Wu and Schacher, 1994). The same phase-contrast views of L7 $(A I)$ and sensory cell $(B 1)$ are viewed with epifluorescence in $A 2$ and $B 2$, respectively. The fluorescent intensities are normalized to the same level for both cells and are depicted in pseudocolor with high (red) or low (dark blue) levels of apCAM (range of pixel intensity between 0 and 75 arbitrary units). Note that the initial segment of L7 (arrowhead in A) and two axon stumps (arrows in A) show "hot spots" or patches of high-intensity staining. Stripes of higher intensity are also common along the axon. On average, the regenerated distal neurites of $\mathrm{L} 7$ are stained at a relatively low intensity. The growth cones of the sensory cell (small arrows in $B$ ), as well as the neurites, axon stump (large arrow in $B$ ) and the initial segment (arrowhead in $B$ ) of the sensory cell are stained at a low intensity relative to the major axon of L7. Scale bar, $50 \mu \mathrm{m}$. 


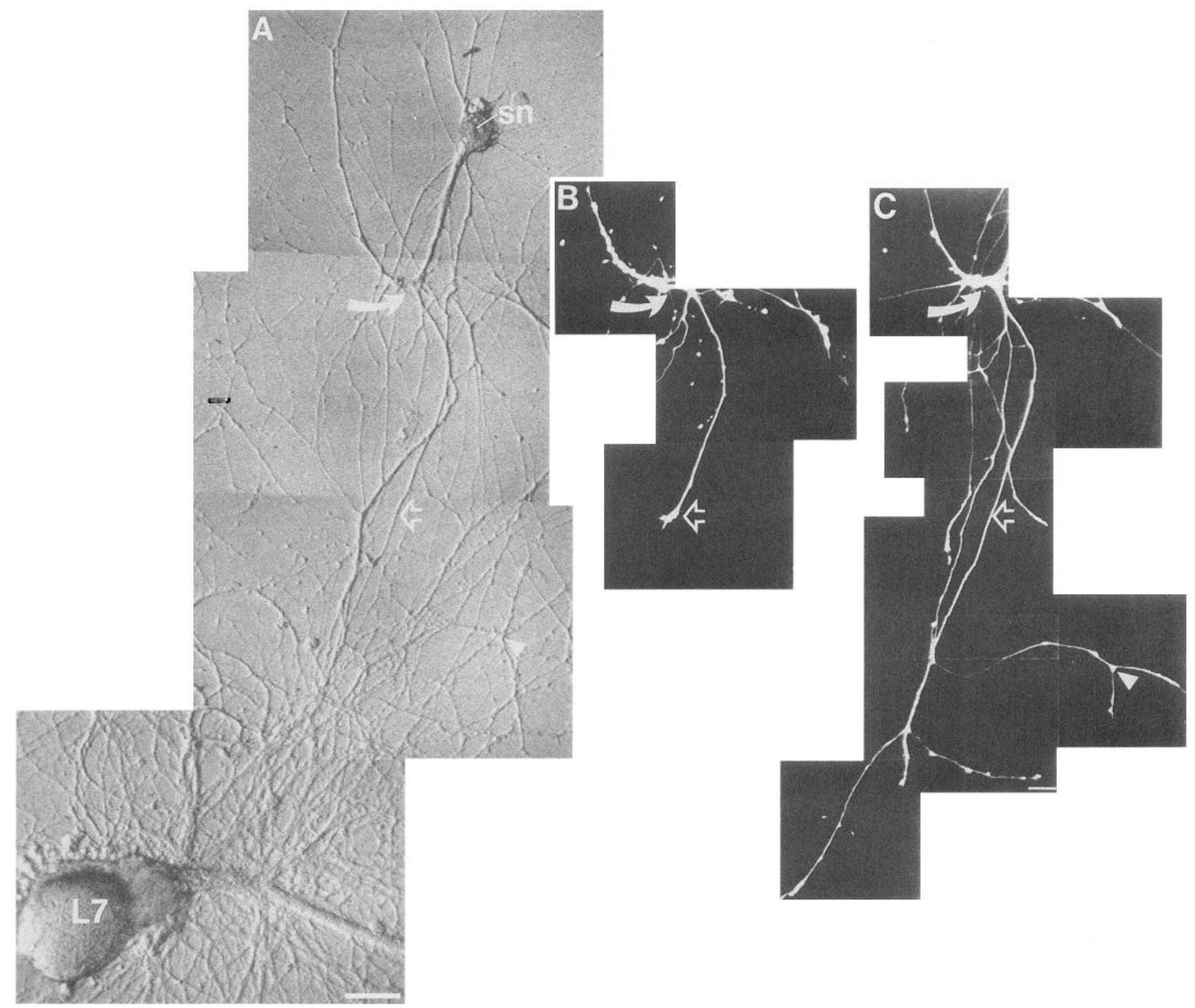

Figure 5. The structure of sensory neurites is relatively simple when interacting with the distal neurites of L7. A, Nomarski contrast view of SNL7 culture on day 3 . The sensory cell was plated about $600 \mu \mathrm{m}$ from the proximal axons of the target motor neuron L7. The large arrow points to the axon stump of the sensory cell; the open arrow points to location of a sensory growth cone on day 2; small arrowhead added as reference point. $B$, Epifluorescent photograph of sensory neurites emerging from axon stump (solid arrow) and extending toward the motor axon on day 2 following injection of 5(6)-carboxyfluorescein. One growth cone (open arrow) has made contact with the most distal motor neurites at this time. $C$, Epifluorescent photograph of regenerated sensory neurites $24 \mathrm{hr}$ later. Sensory neurites have extended substantially and made contacts with many distal motor neurites, but the growth pattern remains relatively simple; sensory neurites extend in fasciculated thick bundles with few varicosities formed while contacting distal neurites of $\mathrm{L} 7$. Scale bars: $A, 70 \mu \mathrm{m} ; B$ and $C, 30 \mu \mathrm{m}$.

number of new sensory growth cones extending along the proximal axons of $\mathrm{L} 7(4.1 \pm 1.1$ for control vs $11.8 \pm 2.2$ for 5 -HT). These results are consistent with the hypothesis that 5-HT enhances synapse formation by simultaneously decreasing sensory-sensory interactions while increasing sensory-motor interactions.

\section{Discussion}

Our results suggest that the regional distribution of a single type of cell adhesion molecule on the surfaces of both the potential target and the ingrowing presynaptic processes may influence the direction and pattern of growth by the presynaptic growth

Figure 6. 5-HT changes the structure of regenerating sensory neurites interacting with distal neurites of L7. A, Nomarski contrast photograph of SN-L7 culture on day 3. The sensory cell was plated about $500 \mu \mathrm{m}$ from the stump of one of the proximal axons of the target motor neuron L7. Arrows indicate reference points. B, Epifluorescent photograph of all regenerated sensory neurites contacting the distal neurites of L7 on day 2. Arrow indicates reference point. $C$, Epifluorescent photograph of regenerated sensory neurites contacting distal neurites of L7 $24 \mathrm{hr}$ later and following applications of 5-HT. New sensory neurites branch extensively and form numerous varicosities; a pattern of growth that is more typical of sensory neurites contacting the proximal axons of L7 (see Figs. 1, 2). The arrows indicate reference points. Scale bars: $A, 70 \mu \mathrm{m} ; B$ and $C, 30 \mu \mathrm{m}$. 

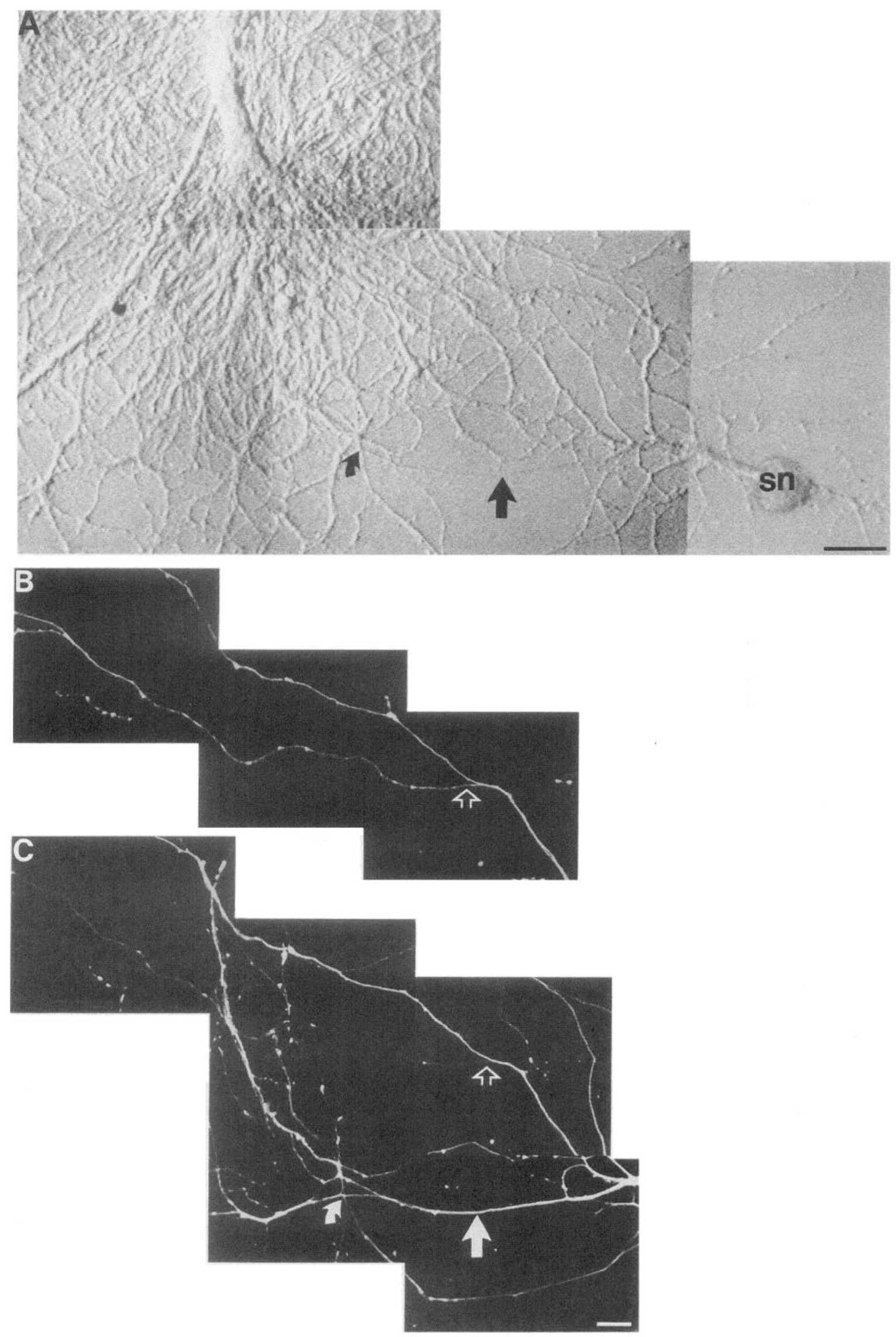


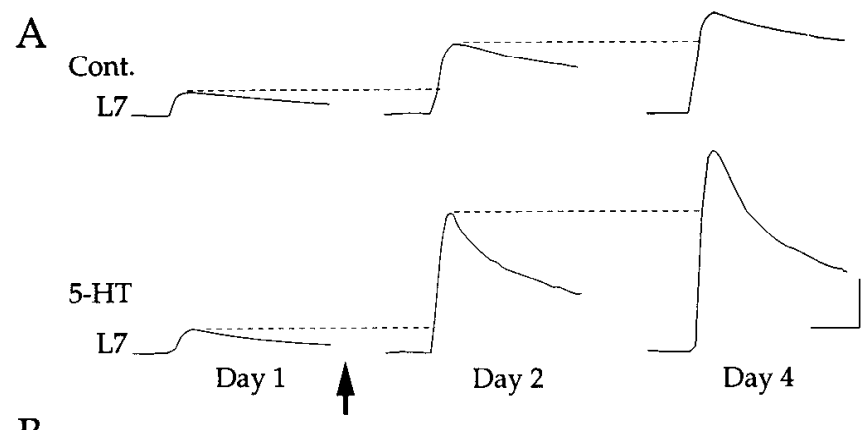

B

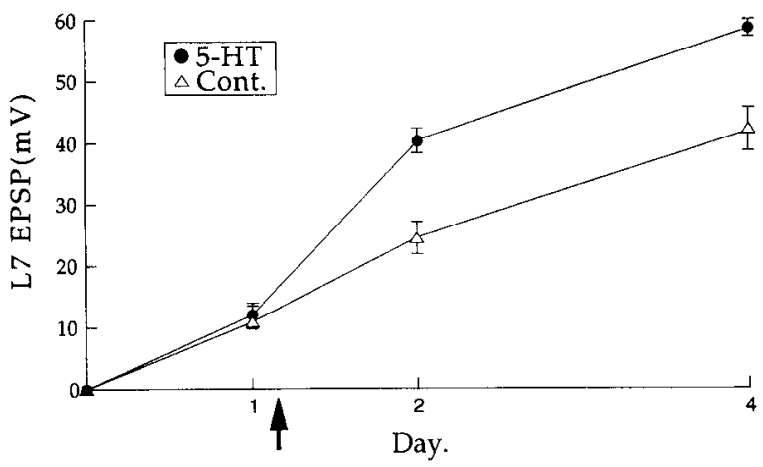

Figure 7. Early application of 5-HT increases the rate of synapse formation. $A$, Excitatory postsynaptic potentials (EPSPs) evoked in L7 before (day 1) and after (day 2 and day 4) control (Cont.) and serotonin (5-HT) treatments (arrow) given on day 1. Calibration: $15 \mathrm{mV}, 12.5$ msec. $B$. Summary of the change evoked by $5-\mathrm{HT}$ in the time-dependent development of the EPSP evoked in L7. The EPSP was recorded from the same set of control and 5-HT-treated cultures on days 1,2, and 4 . Each point is the mean and SEM of the amplitude of the EPSP. Note that 5-HT evoked a significant increase in the amplitude of the EPSP recorded on day 2. A two-factor ANOVA indicated a significant effect of treatment $[F(2,20)=10.094, p<0.001]$, and a comparison at each time point (corrected for multiple groups) indicated a significant effect of treatment $(F=14.183, p<0.008)$ on day 2 . The difference in the amplitude of the EPSP produced by 5-HT is maintained on day 4 ( $F$ $=9.600, p<0.02$ ), suggesting that 5 -HT did not disrupt the ongoing development of this connection.

cones as well as the formation of structures associated with synaptic contacts. The preference of the sensory growth cone to extend along the surfaces of the proximal axons of L7 (Glanzman et al., $1989,1990,1991)$ correlates with the high level of expression of apCAM. Thus, the overall pattern of growth by a presynaptic cell when contacting potential zones within a target region may be influenced by the same types of reciprocal ligandreceptor interactions between the surfaces of the cells that may mediate growth cone responses for different substrates during axonal guidance (Landmesser, 1980; Goodman et al., 1984; Cox et al., 1990; Raper and Kapfhammer, 1990; Kuwada, 1992; Schwabe et al., 1993). When sensory cell growth cones are given a choice between extending along the substrate or other sensory neurites, there is a preference for the sensory neurites (Peter et al., 1994). The distal motor neurites on average express a level of anti-apCAM fluorescence that is about $40 \%$ greater than that observed for sensory neurites. This difference correlates with a small increase in branching and in the number of varicosities formed by sensory neurites with distal motor neurites compared to the growth pattern observed with interactions with other sensory neurites (Glanzman et al., 1989). The most profound change in growth is associated with the original proximal motor axons that express nearly a threefold higher level of anti-apCAM fluorescence compared to the distal motor neurites. Thus, as a sensory growth cone contacts this region it fasciculates with the major motor process and extends along it rather than other neighboring sensory or motor neurites. This correlation suggest that the sensory growth cone may be capable of detecting differences in apCAM levels either at a choice point or along a gradient. Such choices within a target region may contribute to the mechanism by which homogeneous populations of presynaptic axons (e.g., motor neurons or retinal ganglion cells) select specific zones within a homogeneous population of target cells to establish connections (Sperry, 1963; Trisler et al., 1981; Stryker and Harris, 1986; Shatz, 1990; Baier and Bonhoeffer, 1992; Goodman and Shatz, 1993; Kishishian et al., 1993; Sanes, 1993). Although we cannot rule out the possibility that other surface molecules are mediating some of the target-dependent structural changes in the sensory cell, the fact that apCAM isoforms make up a large fraction of total membrane protein (Keller and Schacher, 1990) favors the importance of these molecules in contributing to the process of synapse formation between the sensory and motor cells. This role in synapse formation is supported by the profound changes in sensory cell growth and synapse formation when anti-apCAM $\mathrm{mAb}$ bound on the motor axon alone interferes with sensory neurite fasciculation with the motor axon and the establishment of effective synaptic connections.

We do not know how regional differences in the level of apCAM expression are generated. Perhaps the original motor axons and dendrites attached to the cell body of $\mathrm{L} 7$ at the time of plating maintain their high levels while insufficient time has elapsed for the insertion of newly synthesized apCAM molecules on the surfaces of the regenerated distal neurites. The high level of apCAM expression at sites of contact between sensory varicosities and the motor axons suggests the possibility that sites of cell-cell interaction may represent regions of preferred insertion or capping of these cell surface molecules, leading to the uneven distribution (Keller and Schacher, 1990; Bailey et al., 1992; Singer, 1992). In addition, the overall distribution of these molecules on either the presynaptic or postsynaptic cells may have been influenced by the earlier actions of specific neuromodulators (Bailey et al., 1992; Mayford et al., 1992; Peter et al., 1994; Wu and Schacher, 1994).

One consequence of the selective downregulation of apCAM from the surface of the sensory cells by $5-\mathrm{HT}$ is a shift in the relative ratio of apCAM expression to favor sensory cell interaction with the motor cell. A sensory growth cone, after 5-HT treatment, is given a new cellular substrate choice between a sensory neurite and a distal motor neurite that now show about a twofold difference in the intensity of fluorescently tagged apCAM levels on their surfaces. The calculation of this difference is based on the average 5-HT-induced reduction in apCAM on the surface of the neurites of isolated sensory cells and the absence of any change evoked by 5-HT on the distribution of apCAM on L7 neurites (Mayford et al., 1992; Peter et al., 1994). This difference of about $100 \%$, compared to a $40 \%$ differential in anti-apCAM fluorescence in control situations, may now be large enough to contribute to the 5-HT-induced change in the pattern of growth when sensory neurites contact the distal neurites of $\mathrm{L} 7$.

The mechanism by which a sensory growth cone selects between different cell substrates (even those on the same target cell) which express different levels of apCAM is not known. Second messenger cascades triggered by apCAM interactions at the surface (Atashi et al., 1992; Doherty and Walsh, 1992) may alter cytoskeletal organization affecting growth cone motility 

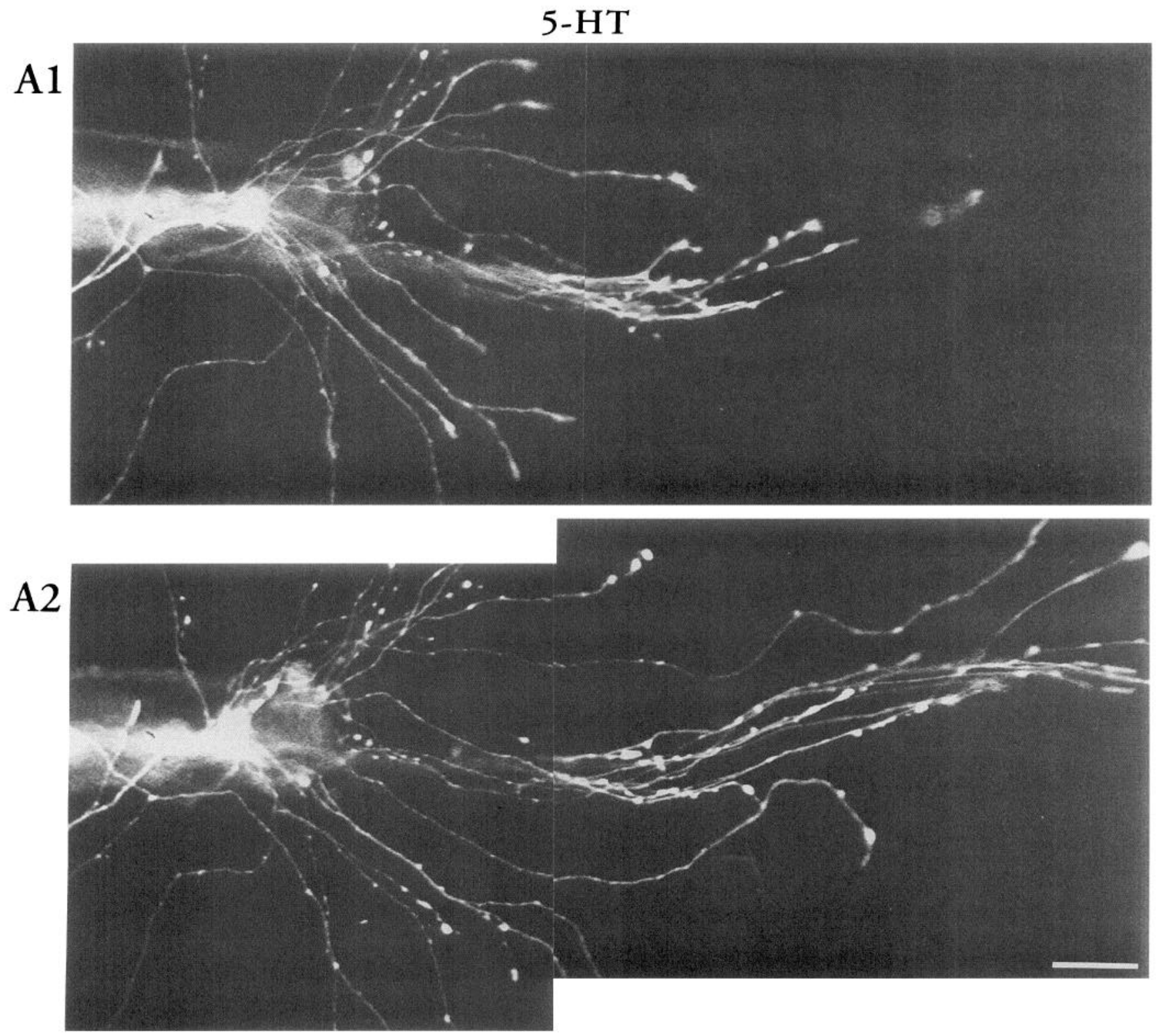

Figure 8. Early application of 5-HT alters the pattern of sensory growth on the proximal axons of L7. A1, Epifluorescent micrograph of sensory neurites growing on the major axon of L7 after $1 \mathrm{~d}$ in culture. The major axon of L7 extends from left to right in the middle of the photograph. The bright fluorescent signal at far left is the sensory axon and stump. Note the sensory neurites extending on the motor axon in the middle of the field. The EPSP evoked in L7 was $15 \mathrm{mV}$. A2, Growth pattern of sensory neurites on L7 axon $24 \mathrm{hr}$ after treatment with 5-HT. Note the appearance of additional growth cones of the extending sensory neurites and new varicosities along individual sensory neurites. The EPSP on day 2 was 46 $\mathrm{mV}$. Scale bar, $30 \mu \mathrm{m}$.

and direction (Forscher et al., 1987; Kater et al., 1988; Lohof et al., 1992). These changes, coupled with the others evoked by 5-HT in the sensory cells-alterations in the expression of a number of proteins including Bip, calmodulin, calriticulin, and the light chain of clathrin (Barzilai et al., 1989; Kennedy et al., 1992; Kuhl et al., 1992; Byrne et al., 1993; Hu et al., 1993), changes in the activity of various protein kinases including PKA and PKC (Kandel and Schwartz, 1982; Occor and Byrne, 1985; Greenberg et al., 1987; Bergold et al., 1990; Saktor and Schwartz, 1990; Byrne et al., 1991; Ghirardi et al., 1992; Sossin and Schwartz, 1992), and the extent of phosphorylation of the substrates of these kinases (Sweatt and Kandel, 1989)-may contribute to the structural changes associated with the formation of new branches and varicosities (Nazif et al., 1991; Schacher et al., 1993). Some of these other changes may contribute to the 5 -HT-induced increase in neurite extension by sensory cells plated with other sensory cells when measured $24 \mathrm{hr}$ after treatment. This effect on the rate of neurite extension is not observed for isolated sensory cells immediately after the 5-HT treatment (Peter et al., 1994), or for sensory cells that have been in culture for $5 \mathrm{~d}$ and are no longer in the active phase of neurite growth (Glanzman et al,, 1990). Thus, 5-HT actions may regulate a number of ongoing processes associated with growth and synapse formation with different kinetics, but cannot initiate those processes in cells that have achieved their final morphology and lack an appropriate synaptic partner.

The exposure to 5-HT during the early stages of SN-L7 interactions appears to accelerate transiently the normal time- 


\section{EPSP Amplitude}

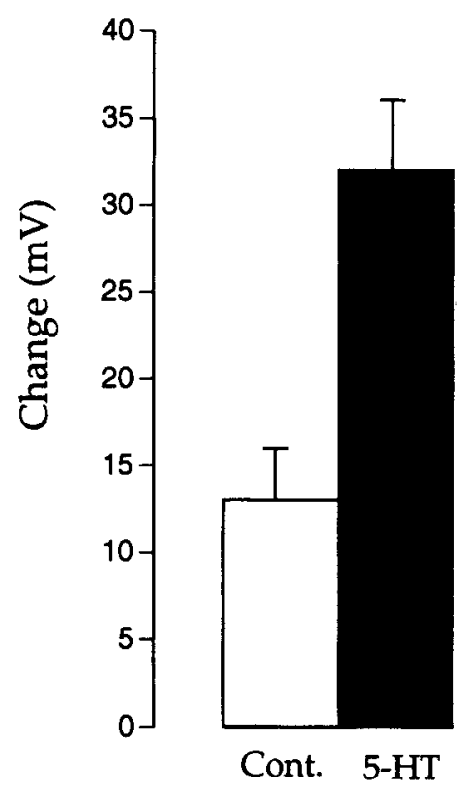

SN Varicosities

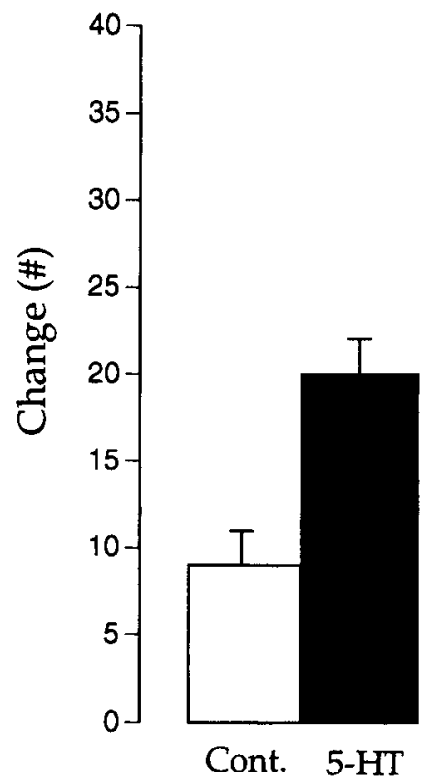

SN Growth Cones

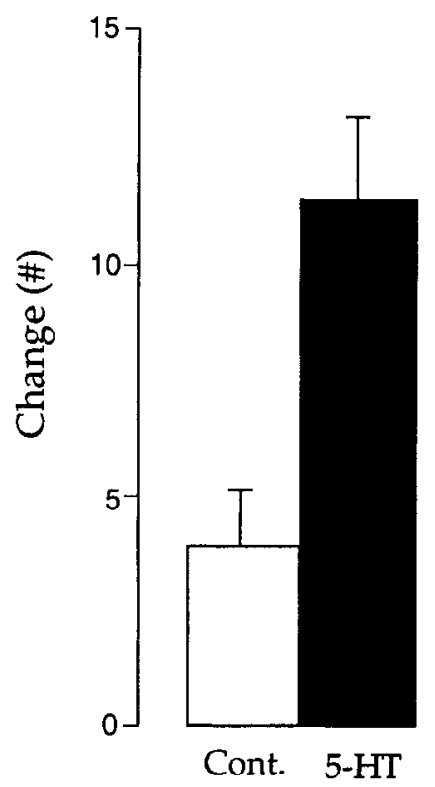

Figure 9. Summary of the functional and structural changes evoked by early treatment with 5-HT. The height of each bar is the mean and SEM of the change in amplitude of the EPSP ( $\mathrm{mV}$ on day 2 minus $\mathrm{mV}$ on day 1), the net change in the number of sensory neuron (SN) varicosities contacting the proximal axons of L7, and the net change in the number of SN growth cones extending exclusively along the proximal axons of L7. An overall ANOVA indicated a significant effect of treatment $[F(2,24)=5.506, p<0.02]$. Treatment had a significant effect on the EPSP $(F=$ $14.369, p<0.005)$, varicosities $(F=18.25, p<0.003)$, and growth cones $(F=9.55, p<0.02)$.

dependent changes in synaptic efficacy. This functional change in efficacy is then maintained for an additional $48 \mathrm{hr}$. The initial functional change in the connection is paralleled by a change in the number of varicosities and branches as was observed for 5-HT treatment of mature connections after $5 \mathrm{~d}$ in culture (Glanzman et al., 1990; Bailey et al., 1992). The downregulation of apCAM from the surface of the sensory cells may also contribute to the initial changes in the developing cultures, especially the increase in the number of sensory growth cones extending along the proximal motor axons. The increase in growth cones may arise from the 5-HT-induced defasciculation of sensory neurites from other sensory neurites (Mayford et al., 1992; Peter et al., 1994). Since each neurite is capable of forming varicosities along the motor axon, a change in the number of sensory branches extending along the axon of the motor cell can lead to a change in the degree of interaction between the surfaces of the sensory neurites and motor axons. This change, in turn, may lead to the formation of more synaptic contacts (Hawver and Schacher, 1993). Thus, cven a relatively small change in the ratio of apCAM expressed by the sensory neurites and the proximal motor axon at a critical point in the formation of synapses can lead to a relatively large change in the overall structure of the sensory cells and in the efficacy of their synaptic connections with the target cells.

The change evoked by early exposure to 5-HT parallels the findings of Greenough et al. (1973, 1985) on the consequence of early experience on the morphological development of various areas of the CNS in vertebrates. Activity-dependent activation of specific pathways during critical periods in the development of neural circuits may enhance the functional and structural features of the activated pathway (Constantine-Paton et al., 1990; Shatz, 1990; Goodman and Shatz, 1993) by modulating the levels of expression or distribution of cell adhesion molecules that continue to be expressed throughout the life of the animal. Additional changes in these circuits via the modulation of NCAM-like molecules with stimuli that evoke behavioral plasticity in the adult animal (Mayford et al., 1992; Cremer et al., 1994) could be mediated in part by the same mechanisms that are first utilized during the formation and stabilization of the connections in development.

\section{References}

Atashi JR, Klinz SG, Ingraham CA, Matten WT, Schachner M, Maness PF (1992) Neural cell adhesion molecules modulate tyrosine phosphorylation of tubulin in nerve growth cone membranes. Neuron 8:831-842.

Baier H, Bonhoeffer F (1992) Axon guidance by gradients of a targetderived component. Science 255:472-475

Bailey CH, Chen M (1983) Morphological basis of long-term habituation and sensitization in Aplysia. Science 220:91-93.

Bailey CH, Chen M (1988) Long-term memory in Aplysia modulates the total number of varicosities of single identified sensory neurons. Proc Natl Acad Sci USA 85:2373-2377.

Bailey CH, Chen M, Keller F, Kandel ER (1992) Serotonin-mediated endocytosis of apCAM: an early step of learning-related synaptic growth in Aplysia. Science 256:645-648.

Bank M, Schacher S (1992) Segregation of presynaptic inputs on an identified target neuron in vitro: Structural remodeling visualized over time. J Neurobiol 12:2960-2972.

Barzilai A, Kennedy TE, Sweatt JD, Kandel ER (1989) 5-HT modulates protein synthesis and the expression of specific proteins during long-term facilitation in Aplysia sensory neurons. Neuron 2:15771586.

Bergold PJ, Sweatt JD, Winicov I, Weiss KR, Kandel ER, Schwartz JH (1990) Protein synthesis during acquisition of long-term facilitation is needed for the persistent loss of regulatory subunits of the Aplysia cAMP-dependent protein kinase. Proc Natl Acad Sci USA 87:37883791.

Bixby JL, Harris WA (1991) Molecular mechanisms of axon growth and guidance. Annu Rev Cell Biol 7:117-159.

Byrne JH, Baxter DA, Buonomano DV, Cleary LJ, Eskin A, Goldsmith 
JR, McClendon E, Nazif FA, Noel F, Scholz KP (1991) Neural and molecular bases of nonassociative and associative learning in Aplysia. Ann NY Acad Sci 627:124-149.

Byrne JH, Zwartjes R, Jomayouni R, Critz SD, Erskin A (1993) Roles of second messenger pathways in neuronal plasticity and in learning and memory. In: Advances in second messenger and phosphoprotein research, Vol 27 (Shennolikar S, Nairn AC, eds), pp 47-108. New York: Raven.

Chow I (1990) Cell-cell interaction during synaptogenesis. J Physiol (Paris) 84:121-127.

Constantine-Paton M, Cline HT, Debski E (1990) Patterned activity, synaptic convergence, and the NMDA receptor in developing visual pathways. Annu Rev Neurosci 13:129-154.

Cox EC, Muller B, Bonhoeffer F (1990) Axonal guidance in the chick visual system: posterior tectal membranes induce collapse of growth cones from the temporal retina. Neuron 2:31-37.

Cremer H, Lange R, Christoph A, Plomann M, Vopper G, Roes J, Brown R, Baldwin S, Kraemer P, Scheff S, Barthels D, Rajewsky K, Wille W (1994) Inactivation of the N-CAM gene in mice results in size reduction of the olfactory bulb and deficits in spatial learning. Nature 367:455-459.

Dale N, Schacher S, Kandel ER (1988) Long-term facilitation in Aplysia involves increases in transmitter release. Science 239:282-285.

Diamond P, Mallavarapu A, Schnipper J, Booth J, Park I, O'Connor TP, Jay DG (1993) Fasciclin I and II have distinct roles in the development of grasshopper pioneer neurons. Neuron 11:409-421.

Doherty P, Walsh FS (1992) Cell adhesion molecules, second messengers and axonal growth. Curr Opin Neurobiol 2:595-601.

Edelman GM (1983) Cell adhesion molecules. Science 219:450-457.

Edelman GM, Cunningham BA (1991) Place-dependent cell adhesion, process retraction, and spatial signalling in neural morphogenesis. Cold Spring Harbor Symp Quant Biol 55:303-318.

Forscher P, Kaczmarek LK, Bunchanan J, Smith SJ (1987) Cyclic AMP induces changes in distribution and transport of organelles within growth cones of Aplysia bag cell neurons. J Neurosci 7:3600-3611.

Fraser SE (1980) Differential adhesion approach to the patterning of nerve connections. Dev Biol 79:453-464.

Furley AJ, Morton SB, Manalo D, Karagogeos D, Dodd J, Jessell TM (1990) The axonal glycoprotein TAG-1 is an immunoglobulin superfamily member with neuritic outgrowth-promoting activity. Cell $61: 157-170$

Ghirardi M, Braha O, Hochner B, Montarolo PG, Kandel ER, Dale N (1992) Roles of Pka and Pkc in facilitation of evoked and spontaneous transmitter release at depressed and nondepressed synapses of Aplysia sensory neurons. Neuron 9:1-20.

Glanzman DL, Kandel ER, Schacher S (1989) Identified target motor neuron regulates neurite outgrowth and synapse formation of Aplysia sensory neurons in vitro. Neuron 3:441-450.

Glanzman DL, Kandel ER, Schacher S (1990) Target-dependent structural changes accompanying long-term synaptic facilitation in Aplysia neurons. Science 249:799-802.

Glanzman DL, Kandel ER, Schacher S (1991) Target-dependent morphological segregation of Aplysia sensory outgrowth in vitro. Neuron 7:903-913.

Goodman CS, Shatz CJ (1993) Developmental mechanisms that generate precise patterns of neuronal connectivity. Cell $72 /$ Neuron 10[Suppl]:77-98.

Greenberg SM, Castellucci VF, Bayley H, Schwartz JH (1987) A molecular mechanism for long-term sensitization in Aplysia. Nature 329: $62-65$.

Greenough WT, Volkmar FR, Juraska JM (1973) Effects of rearing complexity on dendritic branching in frontolateral and temporal cortex of the rat. Exp Neurol 41:371-378.

Greenough WT, Hwang H-M, Gorman C (1985) Evidence for active synapse formation or altered postsynaptic metabolism in visual cortex of rats reared in complex environments. Proc Natl Acad Sci USA 82: $4549-4552$

Grenningloh G, Goodman CS (1992) Pathway recognition by neuronal growth cones: genetic analysis of neural cell adhesion molecules in Drosophila. Curr Opin Neurobiol 2:42-47.

Hall ZW, Sanes JR (1993) Synaptic structure and development: the neuromuscular junction. Cell 72/Neuron 10[Suppl]:99-122.

Hawver DB, Schacher S (1993) Selective fasciculation as a mechanism for the formation of specific chemical connections between Aplysia in vitro. J Neurobiol 24:368-383.
Haydon PG, McCobb DP, Katyer SB (1984) Serotonin selectively inhibits growth cone motility and synaptogenesis of specific identified neurons. Science 226:561-564.

Hu Y, Barzilai A, Chen M, Bailey CH, Kandel ER (1993) 5-HT and cAMP induce the formation of coated pits and vesicles and increase the expression of clathrin light chain in sensory neurons of Aplysia. Neuron 10:921-929.

Kandel ER, Schwartz JH (1982) Molecular biology of learning: modulation of transmitter release. Science 218:433-443.

Kater SB, Mattson MP, Cohan C, Connor J (1988) Calcium regulation of the neuronal growth cone. Trends Neurosci 11:315-321.

Keller F, Schacher S (1990) Neuron-specific membrane glycoproteins promoting neurite fasciculation in Aplysia californica. J Cell Biol 111: 2637-2650.

Kennedy TE, Kuhl D, Barzilai A, Sweatt JD, Kandel ER (1992) Longterm sensitization training in Aplysia leads to an increase in calreticulin, a major presynaptic calcium-binding protein. Neuron 9:10131024.

Kishishian H, Chiba A, Chang TN, Halson MS, Harkins EW, Jarecki J, Wang L, Anderson M, Cash S, Halpern ME, Johanson J (1993) Cellular mechanisms governing synaptic development in Drosophila melanogaster. J Neurobiol 24:757-787.

Klar A, Baldassare M, Jessell TM (1992) F-spondin: a gene expressed at high levels in the floor plate encodes a secreted protein that promotes neural cell adhesion and neurite extension. Cell 69:95-110.

Kuhl D, Kennedy TE, Barzilai A, Kandel ER (1992) Long-term sensitization training in Aplysia leads to an increase in the expression of Bip, the major protein chaperon of the endoplasmic reticulum. J Cell Biol 119:1069-1076.

Kuwada JY (1992) Growth cone guidance in the zebrafish central nervous system. Curr Opin Neurobiol 2:31-35.

Landmesser LT (1980) The generation of neuromuscular specificity Ann Rev Neurosci 3:279-302.

Landmesser LT, Dahm L, Tang J, Rutishauser U (1990) Polysialic acid as a regulator of intramuscular nerve branching during embryonic development. Neuron 4:655-667.

Lohof AM, Quillan M, Dan Y, Poo M-m (1992) Asymmetric modulation of cytosolic cAMP activity induces growth cone turning. $J$ Neurosci 12:1253-1261.

Lumsden AGS, Davies AM (1983) Earliest sensory nerve fibers are guided to peripheral targets by attractants other than nerve growth factor. Nature 306:786-788.

Mayford M, Barzilai A, Keller F, Schacher S, Kandel ER (1992) Modulation of an NCAM-related adhesion molecule with long-term synaptic plasticity in Aplysia. Science 256:638-644.

Montarolo PG, Goelet P, Castellucci VF, Morgan J, Kandel ER, Schacher S (1986) A critical period for macromolecular synthesis in longterm heterosynaptic facilitation in Aplysia. Science 234:1249-1254.

Montarolo PG, Kandel ER, Schacher S (1988) Long-term heterosynaptic inhibition in Aplysia. Nature 333:171-174.

Nazif FA, Byrne JH, Cleary LJ (1991) cAMP induces long-term morphological changes in sensory neurons of Aplysia. Brain Res 539:324327.

Occor KA, Byrne JH (1985) Membrane responses and changes in cyclic AMP levels in Aplysia neurons by serotonin, tryptamine, FMRFamide, and small cardioactive peptide ( $\mathrm{SCPb})$. Neurosci Lett 55:113-118.

Peter N, Aronoff B, Wu F, Schacher S (1994) Decrease in growth coneneurite fasciculation by sensory or motor cells in vitro accompanies modulation of Aplysia cell adhesion molecules by neurotransmitters. J Neurosci 14:1413-1421.

Pini A (1993) Chemorepulsion of axons in the developing mammalian central nervous system. Science 261:95-98.

Raper JA, Kapfhammer JP (1990) The enrichment of a neuronal growth cone collapsing activity from the embryonic chick brain. Neuron 4:21-29.

Rayport SG, Schacher S (1986) Synaptic plasticity in vitro: cell culture of identified Aplysia neurons mediating short-term habituation and sensitization. J Neurosci 6:759-763.

Reichardt LF, Tomaselli KJ (1991) Extracellular matrix molecules and their receptors: functions in neural development. Annu Rev Neurosci 14:531-570.

Rutishauser U, Jessell TM (1988) Cell adhesion molecules in vertebrate neural development. Physiol Rev 68:819-857.

Rutishauser U, Acheson A, Hall A, Mann D, Sunshine J (1988) The 
neural cell adhesion molecule (NCAM) as a regulator of cell-cell interactions. Science 240:53-57.

Saktor TC, Schwartz JH (1990) Sensitizing stimuli cause translocation of protein kinase C in Aplysia sensory neurons. Proc Natl Acad Sci USA 87:2036-2039.

Sanes JR (1993) Topographic maps and molecular gradients. Curr Opin Neurobiol 3:67-74.

Schacher S (1985) Differential synapse formation and neurite outgrowth at two branches of the metacerebral cell of Aplysia in dissociated cell culture. J Neurosci 5:2028-2034.

Schacher S, Montarolo PG (1991) Target-dependent structural changes in sensory neurons of Aplysia accompany long-term heterosynaptic inhibition. Neuron 6:679-690.

Schacher S, Proshansky E (1983) Neurite regeneration by Aplysia neurons in dissociated cell culture: modulation by Aplysia hemolymph and the presence of the initial axonal segment. J Neurosci 3:24032413.

Schacher S, Montarolo PG, Kandel ER (1990) Selective short- and long-term effects of serotonin, small cardioactive peptide, and tetanic stimulation on sensorimotor synapses of Aplysia in culture. J Neurosci 10:3286-3294.

Schacher S, Glanzman D, Barzilai A, Dash P, Grant SG, Keller F, Mayford M, Kandel ER (1991) Long-term facilitation in Aplysia: persistent phosphorylation and structural changes. Cold Spring Harbor Symp Quant Biol 55:187-202.

Schacher S, Kandel ER, Montarolo PG (1993) cAMP and arachidonic acid simulate long-term structural and functional changes produced by neurotransmitters in Aplysia sensory neurons. Neuron 10:10791088.
Schwab ME, Kapfhammer JP, Bandlow CE (1993) Inhibitors of neurite growth. Annu Rev Neurosci 16:565-595.

Shatz CJ (1990) Impulse activity and the patterning of connections during CNS development. Neuron 5:745-756.

Singer SJ (1992) Intracellular communication and cell-cell adhesion. Science 255:1671-1677.

Sossin WS, Schwartz JH (1992) Selective activation of calcium-activated PKCs in Aplysia neurons by 5-HT. J Neurosci 9:3218-3229.

Sperry RW (1963) Chemoaffinity in the orderly growth of nerve fiber patterns and connections. Proc Natl Acad Sci USA 50:703-710.

Stryker MP, Harris WA (1986) Binocular impulse blockade prevents the formation of ocular dominance columns in cat visual cortex. J Neurosci 6:2117-2133.

Sweatt JD, Kandel ER (1989) Persistent and transcriptionally dependent increase in protein phosphorylation in long-term facilitation of Aplysia neurons. Nature 339:51-54.

Takeichi M (1991) Cadherin cell adhesion receptors as a morphogenetic regulator. Science 251:1451-1455.

Tessier-Lavigne M, Placzek M, Lumsden AGS, Dodd J, Jessell TM (1988) Chemotropic guidance of developing axons in the mammalian central nervous system. Nature 336:775-778.

Trisler GD, Schneider MD, Nirenberg M (1981) A topographic gradient of molecules in the retina can be used to identify neuron position. Proc Natl Acad Sci USA 78:2145-2149.

Wu F, Schacher S (1994) Pre- and postsynaptic changes mediated by two second messengers contribute to the expression of Aplysia longterm heterosynaptic inhibition. Neuron 12:407-421. 